\title{
Adubação nitrogenada na cultura do feijoeiro em plantio convencional
}

\author{
Nitrogen management in bean crop planted in conventional tillage \\ Antônio Luis Santi ${ }^{1}$ Luiz Marcelo Costa Dutra ${ }^{2}$ Thomas Newton Martin ${ }^{3}$ \\ Rafael Bonadiman ${ }^{4}$ Gustavo Luiz Bellé ${ }^{4}$ Lisandra Pinto Della Flora ${ }^{4}$ \\ Adilson Jauer
}

\section{RESUMO}

As cultivares de feijão "TPS Nobre" e "Pérola" foram utilizadas durante a safra de 2001/2002 em Santa Maria -RS, com o objetivo de determinar a melhor época de aplicação e o fracionamento mais adequado da adubação nitrogenada que poderão ser adotados no sistema de plantio convencional. O nitrogênio foi aplicado na semeadura $\left(15 \mathrm{~kg} \mathrm{ha}^{-1} \mathrm{em}\right.$ todos os tratamentos) e em uma única dose aos 14, 21, 28 e 35 DAE, sendo fracionado nas mesmas épocas em duas aplicações: $50 \%+50 \%$ da dose, $30 \%+70 \%$ da dose, $70 \%+30 \%$ da dose. $O$ delineamento experimental utilizado foi o de blocos ao acaso, com parcelas subdivididas. Não foi verificada a interação entre a adubação nitrogenada e a época de aplicação. Além disso, a cultivar "TPS Nobre" obteve um rendimento de grãos $49 \%$ superior à cultivar "Pérola". O maior rendimento de grãos foi obtido por meio da aplicação de 100\% da adubação nitrogenada aos 21 dias após a emergência, porém bons resultados são obtidos com o fracionamento da adubação nitrogenada (50\% $14 \mathrm{DAE}+50 \% 21 \mathrm{DAE}),(70 \% 14 \mathrm{DAE}+$ $30 \% 28 \mathrm{DAE})$ e (30\% $21 \mathrm{DAE}+70 \% 28 \mathrm{DAE})$. A aplicação nitrogenada após os 28 DAE não apresentou resultados favoráveis à obtenção de elevados rendimentos de grãos.

Palavras-chave: Phaseolus vulgaris L., nitrogênio, cultivar.

\section{ABSTRACT}

The beans varietes, 'TPS Nobre' and 'Pérola' were grown during the summer season of 2001/2002, in Santa Maria, State of Rio Grande do Sul, Brazil, with the objectives of study the application timing and spplitting of nitrogem in conventional tillage. The nitrogen was applied at planting (15 $\mathrm{kg} \mathrm{ha}^{-1}$ in all treatments) a single rate at 14, 21, 28 and 35 $D A E$ and at the same times in two applications: $50 \%+50 \%$ of the dose, $30 \%+70 \%$ of the dose, $70 \%+30 \%$ of the dose. The experimental was in randomized blocks design with four replications, with split-plot. It was not verified interaction between time and nitrogen portionin. Moreover, 'TPS Nobre' grain yield was 49\% higher than variety Pérola. Higher grain yield was obtained through the application of nitrogen full rate at 21 , however good results were obtained with the portionong of the nitrogen fertilization (50\% $14 \mathrm{DAE}+50 \% 21 \mathrm{DAE})$, (70\% $14 \mathrm{DAE}+30 \% 28 \mathrm{DAE})$ e (30\% $21 \mathrm{DAE}+70 \% 28 \mathrm{DAE})$. The nitrogen application after 28 DAE did not provided high grain yields.

Key words: Phaseolus vulgaris L., nitrogen, cultivar.

\section{INTRODUÇÃO}

Considerando a importância na alimentação humana, em função de suas características proteicas e energéticas, o feijão assume papel relevante na dieta alimentar da população de países do terceiro mundo, sendo destacado e incluído em programas governamentais de combate à fome. Neste sentido, é perceptível, nas últimas décadas, o empenho dos pesquisadores em melhoramento vegetal para lançar cultivares de feijão com alto potencial de produtividade

\footnotetext{
${ }^{1}$ Programa de Pós-graduação em Ciência do Solo, Universidade Federal de Santa Maria (UFSM), Santa Maria, RS, Brasil. E-mail santial@mail.ufsm.br.

${ }^{2}$ Departamento de Fitotecnia, UFSM, 97119-900, Santa Maria, RS, Brasil. E-mail: marcelo@ccr.ufsm.br.

${ }^{3}$ Programa de Pós-graduação em Fitotecnia, Escola Superior de Agricultura “Luiz de Queiroz” (ESALQ), Universidade de São Paulo (USP). E-mail: martin@esalq.usp.br. Autor para correspondência.

${ }^{4}$ Curso de Agronomia, UFSM, Santa Maria, RS, Brasil.

${ }^{5}$ Programa de Pós-graduação em Produção Vegetal, UFSM, Santa Maria, RS, Brasil.
} 
e de adaptação aos vários locais e épocas de cultivo. No entanto, os resultados de lavoura mostram que essa capacidade produtiva não está sendo realmente expressada. Isso pode ser explicado pela baixa tecnologia empregada, pelas condições climáticas nem sempre favoráveis e pela carência de informações compatíveis com as cultivares utilizadas, principalmente no que se refere à época, à quantidade e à necessidade de parcelamento da adubação nitrogenada.

O nitrogênio ( $\mathrm{N}$ ) é amplamente destacado e reconhecido pela sua importância no crescimento do feijoeiro e, principalmente, pelo incremento de produtividade (BRAGA et al., 1973; BONSANELLO et al., 1975; BUZETTI et al., 1992). Trabalhos desenvolvidos por OSÓRIO et al. (1976) e por BEM et al. (1977) mostraram efeito positivo das épocas de aplicação sobre o rendimento do feijoeiro, ao passo que KORNELIUS et al. (1975) não o encontraram. O aumento de produtividade foi maior com o aumento da dose de $\mathrm{N}$, independentemente da época de aplicação (SILVA et al., 1977). A adubação nitrogenada logo após a emergência das plântulas proporcionou aumento superior a $81 \%$ na produção de grãos e aumento de 57\% quando empregado aos 22 dias após a emergência (MIYASAKA et al., 1963).

Além de contraditórios, a maioria dos trabalhos com $\mathrm{N}$ foram gerados em condições edafoclimáticas divergentes das preconizadas ou ocorridas durante o ciclo da cultura do feijoeiro no Rio Grande do Sul (RS). As indicações de adubação (N) para a cultura foram geradas na década de 70, a partir das contribuições de PONS et al. (1974), MOURA et al. (1975), OSÓRIO et al. (1976), PONS et al. (1977), MOURA et al. (1979), entre outros.

Objetivou-se determinar a melhor época de aplicação do $\mathrm{N}$ e o fracionamento mais adequado da adubação nitrogenada para o sistema convencional de cultivo em duas cultivares de feijão.

\section{MATERIAL E MÉTODOS}

O experimento foi conduzido em área do Departamento de Fitotecnia, no Campus da Universidade Federal de Santa Maria - RS, região climática da Depressão Central. O clima da região, segundo a classificação de KÖEPPEN (MORENO, 1961), é do tipo Cfa - temperado chuvoso, com chuvas bem distribuídas ao longo do ano, e subtropical do ponto de vista térmico. O solo é um Argissolo Vermelho Distrófico arênico (EMBRAPA, 1999).

A semeadura foi realizada mecanicamente, no dia 12 de outubro de 2001. A data da emergência foi considerada quando 50\% das plântulas haviam emergido. Isso ocorreu aos cinco dias após a semeadura e a colheita ocorreu aos 85 dias após a emergência para as duas cultivares. As cultivares utilizadas foram a "TPS Nobre”, de tipo II, hábito indeterminado, com ramificação ereta e fechada, e a "Pérola”, de tipo III, indeterminado, com ramificação aberta, ambas no sistema de plantio convencional e com uma população de 280.000 plantas ha-1 ${ }^{-}$A adubação da área foi realizada de acordo com os resultados da análise de solo, em concordância com as recomendações da COMISSÃO DE FERTILIDADE DO SOLO - CFSRS/SC (1994), utilizando-se na semeadura $300 \mathrm{~kg} \mathrm{ha}^{-1}$ de adubo mineral NPK na fórmula 5-20-20. A adubação nitrogenada de cobertura foi realizada a lanço, utilizando-se como fonte de $\mathrm{N}$ a uréia (45\% de $\mathrm{N}$ ), na dose de $85 \mathrm{~kg} \mathrm{ha}^{-1}$ de $\mathrm{N}$, disponibilizada toda em uma única aplicação aos 14, 21, 28 e 35 dias após a emergência das plântulas (DAE), e nos parcelamentos: $30 \%+70 \%$ da dose, $50 \%+50 \%$ da dose e $70 \%+30 \%$ da dose, também aplicados nas épocas citadas, constituindo-se nos 22 tratamentos avaliados. As práticas culturais foram aplicadas visando à obtenção do máximo controle de insetos, moléstias e plantas daninhas.

O delineamento experimental utilizado foi o de blocos ao acaso, com parcela subdividida e quatro repetições, em esquema fatorial 2 x 22, cujo primeiro fator correspondeu às cultivares e o segundo às épocas de aplicação e formas de parcelamentos da adubação nitrogenada. As parcelas constituíram-se de 10 linhas espaçadas $0,45 \mathrm{~m}$, com $5,0 \mathrm{~m}$ de comprimento, e com área total de 22,5 $\mathrm{m}^{2}$. Considerou-se como área útil para o rendimento de grãos as duas linhas centrais de cada parcela, descartando-se $0,5 \mathrm{~m}$ de cada extremidade como bordadura, totalizando $3,6 \mathrm{~m}^{2}$.

As variáveis analisadas em cada parcela a partir das plantas compreendidas em 1,0 metro da linha de plantio foram: estatura de plantas (EP), determinada medindo-se a distância $(\mathrm{cm})$ entre a superfície do solo e o último nó vegetativo da haste principal; números de ramos $\mathrm{m}^{-2}$ (NR), somatório dos ramos das plantas da amostra e sua transformação para $\mathrm{m}^{2}$; número de nós na haste principal $\mathrm{m}^{-2}$ (NHP), somatório dos nós das hastes principais das plantas da amostra e sua transformação para $\mathrm{m}^{2}$; número de nós nos ramos $\mathrm{m}^{-2}$ (NNR), somatório dos nós das plantas da amostra e sua transformação para $\mathrm{m}^{2}$; número de vagens na haste principal $\mathrm{m}^{-2}$ (NVP), somatório das vagens inseridas na haste principal da amostra e a sua transformação para $\mathrm{m}^{2}$; número de vagens nos ramos $\mathrm{m}^{-2}$ (NVR), somatório das vagens inseridas nos ramos das plantas da amostra e a sua transformação para $\mathrm{m}^{2}$; altura da base da primeira vagem ao solo (APV), distância entre a 
superfície do solo e a extremidade inferior da vagem (cm); inserção da primeira vagem (IPV), distância entre a superfície do solo e a extremidade inferior da vagem (cm); número de grãos (NG) por planta; rendimento de grãos em kg ha-1 (RG); índice de colheita aparente (ICA), calculado a partir da expressão: ICA = Peso de grãos/ (peso dos grãos + peso da palha); e peso de 100 grãos, determinado a partir do peso, a $13 \%$ de umidade, de quatro repetições de uma amostra de 400 grãos em cada parcela.

Os dados foram analisados com o auxílio do programa NTIA/SOC (EMBRAPA, 1997), por meio da análise de variância (teste F) e da comparação de médias (SCOTT \& KNOTT, 1974).

\section{RESULTADOS E DISCUSSÃO}

A cultura manteve-se, durante o período de cultivo, isenta de pragas, doenças e plantas daninhas que pudessem comprometer o desempenho dos tratamentos. A interação entre os genótipos e os tratamentos não foi significativa para todas as variáveis estudadas.

O rendimento médio de grãos para as cultivares “TPS Nobre” e "Pérola” (Tabela 1) foi de $2.742 \mathrm{~kg} \mathrm{ha}^{-1} \mathrm{e} 1.845 \mathrm{~kg} \mathrm{ha}^{-1}$, respectivamente. O maior rendimento da “TPS Nobre” justifica-se pelo maior potencial genético e pelas características intrínsecas da cultivar, o que se traduziu no maior número de legumes na haste principal e no maior número de grãos (Tabela 1) do que a cultivar Pérola. O número de nós, tanto nos ramos quanto na haste principal (Tabela 1), também explica em parte a superioridade produtiva da “TPS Nobre”, pois, segundo PORTES (1996), há uma correlação entre o número de nós e o número de unidades reprodutivas (flores), refletindo-se no número de legumes.

As variáveis número de nós na haste principal, número de nós nos ramos, número de legumes na haste principal, número de grãos, rendimento de grãos, índice de colheita e peso de cem grãos apresentaram diferenças entre os dois genótipos estudados. A cultivar “TPS Nobre” mostrou-se superior à cultivar Pérola em todas as variáveis citadas anteriormente, exceto no índice de colheita e no peso de cem grãos, sendo a cultivar "Pérola” então superior. Apesar de a cultivar "Pérola” ter sido superior à “TPS Nobre” quanto à massa de 100 grãos, a magnitude desta diferença foi insuficiente para causar alterações no rendimento de grãos, pois, nos demais componentes do rendimento, as variações não foram significativas. Essa é uma característica particular da cultivar "Pérola" descrita pela COMISSÃO ESTADUAL DE PESQUISA
DE FEIJÃO - CEPEF (2001), mostrando a como possuidora de um peso de $27 \mathrm{~g}$, enquanto a "TPS Nobre” apresenta 18,4g. As demais variáveis não apresentaram diferença pelo teste $\mathrm{F}$.

Os rendimentos médios foram inferiores na avaliação de genótipos de feijão em duas épocas de cultivo (safra e safrinha), obtendo respectivamente 2.089 $\mathrm{kg} \mathrm{ha}^{-1}$ e $712 \mathrm{~kg} \mathrm{ha}^{-1}$ (POSSEBON, et al., 2003). As cultivares em estudo obtiveram $2.308 \mathrm{~kg} \mathrm{ha}^{-1}$ como média de produção, sendo que a "TPS Nobre" obteve um rendimento $48 \%$ superior ao rendimento da cultivar "Pérola".

Para o rendimento de grãos, o coeficiente de variação foi de 27,15\%, sendo classificado como precisão média (LÚCIO, 1997). Mesmo assim, as cultivares apresentaram diferenças significativas entre si por meio do teste $\mathrm{F}$, a 5\% de probabilidade de erro.

A estatura média de plantas foi de $60,32 \mathrm{~cm}$, a altura média da vagem de $16,89 \mathrm{~cm}$ e a inserção da primeira vagem de $25,37 \mathrm{~cm}$, dados que não diferiram entre as cultivares (Tabela 1). Em termos numéricos e pelas observações de campo, seria possível a realização de colheita mecanizada para as cultivares em estudo. Para a cultivar "TPS Nobre”, a aplicação de N aos 15 DAE promoveu plantas de maior altura e vagens com inserção mais alta, quando comparadas às resultantes de $\mathrm{N}$ aplicado aos 30 DAE (ZAGONEL et al., 2002). Segundo esses autores, tais ganhos foram benéficos no sentido de evitar perdas pela barra de corte da colhedora. Pensando em reduzir as perdas na colheita, quando esta for realizada mecanicamente, as aplicações mais precoces do $\mathrm{N}$ podem ser uma estratégia de manejo interessante, devendo ser melhor estudada.

O índice de colheita aparente (ICA) sugere que podem haver respostas diferenciadas quanto à eficiência na translocação do N para a produção de grãos em função da cultivar utilizada (Tabela 1). Trabalhando com doses de $\mathrm{N}$ aplicadas 30\% na semeadura e 70\% de 20 a 25 DAE, SILVA et al. (1989) mencionaram o índice de colheita como um indicador da eficiência da absorção e da utilização do $\mathrm{N}$ disponível no solo. Como o rendimento de grãos diferiu significativamente entre as cultivares, essa possibilidade deve ser considerada principalmente quando se trabalhar com doses dentro de épocas de aplicação, pois, conforme esses autores, a capacidade exploratória do sistema radicular é uma função da cultivar utilizada determinando, conseqüentemente, a absorção do N e sua conversão em produtividade.

Não foram observadas alterações nos estádios de desenvolvimento das plantas em função dos tratamentos ou da cultivar utilizada. Mesmo assim, as aplicações do N, considerando DAE ou até mesmo 
Tabela 1 - Média das cultivares para as variáveis: estatura de plantas (EP); números de ramos m ${ }^{-2}$ (NR); número de nós na haste principal m ${ }^{-2}$ (NHP); número de nós nos ramos $\mathrm{m}^{-2}$ (NNR); número de vagens na haste principal $\mathrm{m}^{-2}$ (NVP); número de vagens nos ramos ${ }^{-2}$ (NVR); altura da base da primeira vagem ao solo (APV); inserção da primeira vagem (IPV); número de grãos (NG); rendimento de grãos kg ha-1 (RG); índice de colheita aparente (ICA); peso de cem grãos (PCG); média geral e coeficiente de variação (CV). Santa Maria - RS, 2002.

\begin{tabular}{|c|c|c|c|c|c|c|}
\hline Cultivares & $\mathrm{EP}(\mathrm{cm})$ & NR & NHP & NNR & NVP & NVR \\
\hline TPS Nobre & $61,41^{\mathrm{ns}}$ & $1,82^{\mathrm{ns}}$ & $12,70^{*}$ & $8,44^{*}$ & $6,23 *$ & $6,62^{\mathrm{ns}}$ \\
\hline Pérola & 59,16 & 1,95 & 10,01 & 7,11 & 3,82 & 5,86 \\
\hline Média & 60,32 & 1,88 & 11,39 & 7,8 & 5,07 & 6,07 \\
\hline \multirow[t]{2}{*}{$\mathrm{CV}$} & 14,90 & 41,85 & 11,52 & 49,69 & 30,86 & 58,87 \\
\hline & APV & IPV & NG & $\mathrm{RG}\left(\mathrm{kg} \mathrm{ha}^{-1}\right)$ & ICA & PCG \\
\hline TPS Nobre & $17,99^{\mathrm{ns}}$ & $26,32^{\mathrm{ns}}$ & $60,98 *$ & $2742,12 *$ & $0,41^{*}$ & $21,16^{*}$ \\
\hline Pérola & 15,71 & 24,36 & 37,59 & 1845,73 & 0,46 & 29,02 \\
\hline Média & 16,89 & 25,37 & 49,66 & 2308,2 & 0,43 & 24,96 \\
\hline $\mathrm{CV}$ & 37,86 & 37,56 & 45,52 & 27,15 & 24,88 & 6,92 \\
\hline
\end{tabular}

$* \mathrm{e}^{\mathrm{ns}}$ : significativo e não significativo pelo teste $\mathrm{F}$, ao nível de 5\% de probabilidade de erro, respectivamente.

em semanas após a emergência das plântulas, como o sugerido pelas atuais recomendações, devem ser vistas com cautela, uma vez que o manejo em função da idade cronológica pode ser influenciado pelas variações no desenvolvimento da cultura, pela região, pela época de semeadura ou pela cultivar utilizada.

Na tabela 2, pode-se observar que o tratamento que apresentou o maior rendimento de grãos foi o T2, ou seja, $100 \%$ da adubação nitrogenada aplicada aos 21 DAE. Apesar dos tratamentos T6 (50\% $14 \mathrm{DAE}+50 \% 21 \mathrm{DAE}), \mathrm{T} 10(70 \% 14 \mathrm{DAE}+30 \% 28$ DAE) e T14 (30\% 21 DAE + 70\% 28 DAE) estarem na segunda posição quanto à classificação dos tratamentos, é válida a ressalva de que o parcelamento da adubação nitrogenada deve ser adotado como uma atitude técnica racional e alternativa para a redução de riscos e de probabilidade de perdas do $\mathrm{N}$ mineral. Economicamente, a execução de tal prática de manejo deve levar em conta o tamanho da área, as condições climáticas e a disponibilidade de mão-de-obra na propriedade.

Um fator importante que deve ser considerado é o regime hídrico durante a condução do experimento. Todas as datas em que foram aplicados os tratamentos coincidiram com a ocorrência de chuvas. Em função da mobilidade do N no solo, tal coincidência pode ter gerado perdas significativas por lixiviação. $\mathrm{O}$ total de precipitação durante todo o ciclo da cultura foi de $291 \mathrm{~mm}$, sendo que deste, $70 \%$ ocorreu no período vegetativo (202,7mm), 14\% (40mm) entre a floração e enchimento de grãos e $17 \%$ (48,3mm) do enchimento de grãos à colheita.
Para fontes nitrogenadas como a uréia, essa forma de distribuição do $\mathrm{N}$ mineral (a lanço) pode resultar em perdas expressivas por volatilização, principalmente quando em solos de textura arenosa e de teor de matéria orgânica baixa, cuja capacidade de retenção de amônia é limitada (RODRIGUES \& KIEHL, 1986). Além disso, ALMEIDA et al. (2000) sugerem que as respostas à aplicação do $\mathrm{N}$ podem ser afetadas por qualquer tipo e nível de estresse devido ao ciclo curto da cultura, ao sistema radicular pouco desenvolvido, à cultivar utilizada, às condições de clima e à situação do solo no local de semeadura, como, por exemplo, cultura anterior, teor de matéria orgânica, compactação do solo, textura e irrigação, o que permite respostas diferenciadas de um ano para outro até mesmo na própria área.

Com a aplicação fracionada das doses de nitrogênio em épocas mais tardias, como no caso dos tratamentos T20, T21 e T22, existe uma tendência do rendimento de grãos ser prejudicado, apresentando produtividades mais baixas quando comparadas às dos demais tratamentos (Tabela 2). Sendo assim, não seria pertinente a aplicação de elevadas quantidades de nitrogênio em períodos superiores a $28 \mathrm{DAE}$. Segundo BARBOSA FILHO et al. (2004, 2005), aplicar N duas ou três vezes resulta em um rendimento de grãos significativamente maior do que aplicá-lo apenas uma vez, aos 30 DAE. A dose pode variar de 120 a $150 \mathrm{~kg} \mathrm{ha}^{-1}$ de $\mathrm{N}$, sendo a uréia o fertilizante que apresentou maior margem de lucro. A aplicação de $\mathrm{N}$ fonte uréia na superfície do solo, seguida de irrigação, é a opção mais econômica de adubação nitrogenada em cobertura para 
Tabela 2 - Média dos tratamentos para as variáveis: estatura de plantas (EP); números de ramos m² (NR); número de nós na haste principal $\mathrm{m}^{-2}$ (NHP); número de nós nos ramos $\mathrm{m}^{-2}$ (NNR); número de vagens na haste principal $\mathrm{m}^{-2}$ (NVP); número de vagens nos ramos $\mathrm{m}^{-2}$ (NVR); altura da base da primeira vagem ao solo (APV); inserção da primeira vagem (IPV); número de grãos (NG); rendimento de grãos $\mathrm{kg} \mathrm{ha}^{-1}$ (RG); índice de colheita aparente (ICA) e peso de cem grãos (PCG). Santa Maria - RS, 2002.

\begin{tabular}{|c|c|c|c|c|c|c|}
\hline Tratamentos & $\mathrm{EP}(\mathrm{cm})$ & NR & NHP & NNR & NVP & NVR \\
\hline $\mathrm{T} 1$ & $61,12 c^{*}$ & $1,36 \mathrm{~g}$ & 11,19 e & $5,17 \mathrm{~h}$ & 5,66 a & $4,39 \mathrm{~d}$ \\
\hline Т 2 & 61,82 c & $1,79 \mathrm{f}$ & 11,94 c & $7,77 \mathrm{~d}$ & 5,66 a & $6,25 \mathrm{~d}$ \\
\hline T 3 & 62,87 c & $1,59 \mathrm{~g}$ & $11,59 \mathrm{e}$ & $6,04 \mathrm{~g}$ & 5,77 a & $4,99 \mathrm{~d}$ \\
\hline $\mathrm{T} 4$ & $57,47 \mathrm{~d}$ & $2,23 \mathrm{c}$ & $10,98 \mathrm{f}$ & $8,27 \mathrm{~d}$ & $4,57 \mathrm{~b}$ & $6,61 \mathrm{~d}$ \\
\hline T 5 & 64,72 b & $1,79 \mathrm{f}$ & 11,98 c & $7,53 \mathrm{~d}$ & 5,51 a & $5,78 \mathrm{~d}$ \\
\hline T 6 & 60,95 c & $2,47 \mathrm{~b}$ & $11,72 \mathrm{~d}$ & $10,60 \mathrm{a}$ & $4,53 \mathrm{~b}$ & $8,79 \mathrm{~b}$ \\
\hline $\mathrm{T} 7$ & $62,50 \mathrm{c}$ & $1,79 \mathrm{f}$ & $11,62 \mathrm{e}$ & $7,74 \mathrm{~d}$ & $5,31 \mathrm{a}$ & $5,63 \mathrm{~d}$ \\
\hline Т 8 & $68,06 \mathrm{a}$ & $2,30 \mathrm{c}$ & $11,61 \mathrm{e}$ & $10,00 \mathrm{c}$ & $4,23 \mathrm{~b}$ & $7,88 \mathrm{c}$ \\
\hline Т 9 & $62,25 \mathrm{c}$ & $1,57 \mathrm{~g}$ & $11,56 \mathrm{e}$ & $6,44 \mathrm{f}$ & 5,07 a & $5,04 \mathrm{~d}$ \\
\hline Т 10 & 60,90 с & $2,26 \mathrm{c}$ & $12,05 \mathrm{a}$ & 10,22 c & 5,49 a & 7,64 c \\
\hline Т 11 & $54,62 \mathrm{~d}$ & 2,49 a & $10,90 \mathrm{f}$ & 10,32 c & $4,23 \mathrm{~b}$ & $10,06 \mathrm{a}$ \\
\hline $\mathrm{T} 12$ & $61,16 \mathrm{c}$ & $1,64 \mathrm{~g}$ & $11,77 \mathrm{~d}$ & $6,79 \mathrm{e}$ & 5,17 a & $5,27 \mathrm{~d}$ \\
\hline Т 13 & $62,29 \mathrm{c}$ & $1,59 \mathrm{~g}$ & $11,53 \mathrm{e}$ & $6,06 \mathrm{~g}$ & 5,66 a & $4,16 \mathrm{~d}$ \\
\hline Т 14 & $58,98 \mathrm{~d}$ & $1,47 \mathrm{~g}$ & $11,29 \mathrm{e}$ & $5,64 \mathrm{~g}$ & 4,97 a & $4,16 \mathrm{~d}$ \\
\hline Т 15 & $65,45 \mathrm{~b}$ & $2,14 \mathrm{c}$ & $12,05 \mathrm{~b}$ & $8,68 \mathrm{~d}$ & 5,39 a & $5,53 \mathrm{~d}$ \\
\hline T 16 & $61,53 \mathrm{c}$ & $1,84 \mathrm{e}$ & $11,96 \mathrm{c}$ & $8,74 \mathrm{~d}$ & 5,12 a & $5,87 \mathrm{~d}$ \\
\hline Т 17 & 61,99 с & $2,13 \mathrm{c}$ & $11,70 \mathrm{~d}$ & $8,13 \mathrm{~d}$ & 5,18 a & $6,55 \mathrm{~d}$ \\
\hline T 18 & 49,91 d & $1,33 \mathrm{~g}$ & $9,27 \mathrm{f}$ & $4,36 \mathrm{~h}$ & $4,40 \mathrm{~b}$ & $3,61 \mathrm{~d}$ \\
\hline Т 19 & $59,16 \mathrm{~d}$ & $2,22 \mathrm{c}$ & $11,47 \mathrm{e}$ & $10,50 \mathrm{~b}$ & $4,63 \mathrm{~b}$ & $7,51 \mathrm{c}$ \\
\hline T 20 & $56,62 \mathrm{~d}$ & $1,54 \mathrm{~g}$ & $10,89 \mathrm{f}$ & $5,68 \mathrm{~g}$ & 5,49 a & $5,73 \mathrm{~d}$ \\
\hline Т 21 & $56,22 \mathrm{~d}$ & $2,05 \mathrm{c}$ & $10,70 \mathrm{f}$ & $8,61 \mathrm{~d}$ & $4,42 \mathrm{~b}$ & $5,96 \mathrm{~d}$ \\
\hline \multirow[t]{2}{*}{ Т 22} & $56,85 \mathrm{~d}$ & $1,88 \mathrm{~d}$ & $11,28 \mathrm{e}$ & $8,30 \mathrm{~d}$ & 5,25 a & $5,54 \mathrm{~d}$ \\
\hline & APV & IPV & NG & $\mathrm{RG}\left(\mathrm{kg} \mathrm{ha}^{-1}\right)$ & ICA & PCG \\
\hline $\mathrm{T} 1$ & $18,30 \mathrm{c}$ & $27,44 \mathrm{c}$ & $47,86 \mathrm{e}$ & 2405,47 c & $0,50 \mathrm{a}$ & $23,97 \mathrm{~d}$ \\
\hline Т 2 & $17,46 \mathrm{c}$ & $26,06 \mathrm{c}$ & $52,47 \mathrm{~d}$ & 2633,23 a & 0,44 a & $24,17 \mathrm{~d}$ \\
\hline Т 3 & 16,82 c & 25,59 c & 49,66 e & 2372,77 c & 0,48 a & $24,56 \mathrm{~d}$ \\
\hline $\mathrm{T} 4$ & $13,86 \mathrm{~d}$ & $22,35 \mathrm{~d}$ & $47,41 \mathrm{e}$ & $2224,07 \mathrm{~d}$ & 0,46 a & $25,95 \mathrm{~b}$ \\
\hline T 5 & $20,87 \mathrm{~b}$ & 29,17 b & $48,01 \mathrm{e}$ & $2089,09 \mathrm{~d}$ & $0,40 \mathrm{~b}$ & $24,00 \mathrm{~d}$ \\
\hline T 6 & $21,10 \mathrm{~b}$ & $29,32 \mathrm{~b}$ & 60,29 a & $2557,89 \mathrm{~b}$ & $0,43 \mathrm{~b}$ & $24,88 d$ \\
\hline T 7 & 22,07 a & $30,70 \mathrm{a}$ & $52,40 \mathrm{~d}$ & $2145,48 d$ & 0,46 a & $24,58 d$ \\
\hline Т 8 & $16,05 \mathrm{~d}$ & $24,46 \mathrm{~d}$ & $51,69 \mathrm{~d}$ & $2052,90 \mathrm{~d}$ & $0,41 \mathrm{~b}$ & $25,09 \mathrm{~d}$ \\
\hline Т 9 & $17,84 \mathrm{c}$ & 26,05 c & $45,01 \mathrm{e}$ & 2391,03 c & 0,44 a & $24,35 \mathrm{~d}$ \\
\hline $\mathrm{T} 10$ & 17,33 c & $25,84 \mathrm{c}$ & 58,46 c & 2563,96 b & $0,48 \mathrm{a}$ & $26,00 \mathrm{~b}$ \\
\hline $\mathrm{T} 11$ & $13,36 \mathrm{~d}$ & $21,87 \mathrm{~d}$ & $60,22 \mathrm{~b}$ & 2321,01 c & $0,42 \mathrm{~b}$ & $25,09 \mathrm{~d}$ \\
\hline Т 12 & $16,01 \mathrm{~d}$ & $24,38 \mathrm{~d}$ & $44,94 \mathrm{e}$ & $2136,54 \mathrm{~d}$ & 0,43 a & $24,01 \mathrm{~d}$ \\
\hline Т 13 & 19,05 c & $27,57 \mathrm{c}$ & 45,89 e & 2404,18 c & $0,39 \mathrm{~b}$ & $24,84 \mathrm{~d}$ \\
\hline T 14 & 18,55 c & 27,15 c & $40,54 \mathrm{e}$ & 2518,73 b & 0,44 a & $25,37 \mathrm{c}$ \\
\hline T 15 & 17,98 c & 27,12 c & $53,62 \mathrm{~d}$ & $2029,70 \mathrm{~d}$ & 0,45 a & $24,70 \mathrm{~d}$ \\
\hline T 16 & $16,45 \mathrm{~d}$ & $24,46 \mathrm{~d}$ & $51,28 \mathrm{~d}$ & $2218,02 \mathrm{~d}$ & 0,45 a & $25,32 \mathrm{c}$ \\
\hline Т 17 & 18,02 c & $26,55 \mathrm{c}$ & $51,69 \mathrm{~d}$ & 2442,40 c & $0,36 \mathrm{~b}$ & $24,76 \mathrm{~d}$ \\
\hline Т 18 & $12,85 \mathrm{~d}$ & $20,40 \mathrm{~d}$ & 58,07 c & 2384,49 c & 0,44 a & $25,60 \mathrm{c}$ \\
\hline Т 19 & $14,30 \mathrm{~d}$ & $23,34 \mathrm{~d}$ & $47,26 \mathrm{e}$ & 2397,50 c & 0,49 a & $25,05 \mathrm{~d}$ \\
\hline T 20 & $14,24 \mathrm{~d}$ & $22,65 \mathrm{~d}$ & 43,74 e & $2262,25 \mathrm{~d}$ & 0,45 a & $26,34 \mathrm{a}$ \\
\hline Т 21 & $13,13 \mathrm{~d}$ & $21,75 \mathrm{~d}$ & $47,37 \mathrm{e}$ & $2244,27 d$ & $0,40 \mathrm{~b}$ & $26,10 \mathrm{~b}$ \\
\hline Т 22 & $15,34 \mathrm{~d}$ & $23,65 d$ & $34,23 \mathrm{e}$ & $2009,56 \mathrm{~d}$ & 0,44 a & $24,49 \mathrm{~d}$ \\
\hline
\end{tabular}

*médias dos tratamentos não seguidos pelas mesmas letras diferem ao nível de 5\% de probabilidade de erro pelo teste de Scoot-Knoot.

Ciência Rural, v.36, n.4, jul-ago, 2006. 
a cultura do feijoeiro irrigado. A recomendação da COMISSÃO DE FERTILIDADE DO SOLO-CFSRS/ SC (1994) é de que o nitrogênio (N) seja aplicado entre duas a três semanas após a emergência das plântulas. ACOMISSÃOESTADUAL DE PESQUISADE FEIJÃO - CEPEF (2001) sugere aplicar entre três a quatro semanas após a emergência das plântulas. Independentemente da recomendação a seguir, é importante observar as condições climáticas para que as perdas sejam reduzidas, estando a adubação nitrogenada nesse intervalo.

Plantas maiores, com a altura do primeiro legumem e inserção da primeira vagem mais distantes do solo, foram obtidas nos tratamentos T7 (70\% 14 $\mathrm{DAE}+30 \% 21 \mathrm{DAE})$ e $\mathrm{T} 8$ (30\% $14 \mathrm{DAE}+70 \% 28$ DAE), respectivamente. Desta forma, pode-se estudar novas estratégias para o favorecimento da colheita mecanizada por meio da aplicação nitrogenada em doses e em épocas que favoreçam o crescimento das plantas.

\section{CONCLUSÕES}

A cultivar "TPS Nobre" obteve um rendimento de grãos 48,56\% superior à cultivar "Pérola”, sendo que não houve interação entre a época da adubação nitrogenada e as cultivares. O melhor rendimento de grãos foi obtido por meio da aplicação de $100 \%$ da adubação nitrogenada aos 21 dias após a emergência. A aplicação do nitrogênio após os 28 DAE não apresenta resultados favoráveis à obtenção de elevados rendimentos de grãos.

\section{AGRADECIMENTOS E APRESENTAÇÃO}

Ao Conselho Nacional de Desenvolvimento Científico e Tecnológico (CNPq), pela concessão de bolsa aos pesquisadores Martin e Bonadiman. À Fundação de Amparo à Pesquisa do Estado do Rio Grande do Sul (FAPERGS), pela concessão de bolsa à pesquisadora Flora. Parte da Dissertação do primeiro autor. Apoio: CNPq.

\section{REFERÊNCIAS}

ALMEIDA, C. et al. Uréia em cobertura e via foliar em feijoeiro. Scientia Agrícola, Piracicaba, v.57, n.2, p.293-298, 2000.

BARBOSA FILHO, M.P. et al. Fontes e métodos de aplicação de nitrogênio em feijoeiro irrigado submetido a três níveis de acidez do solo. Revista Ciência e Agrotecnologia, Lavras, n.28, v.4, p.785-792, 2004.

BARBOSA FILHO, M.P. et al. Fontes, doses e parcelamento da adubação nitrogenada em cobertura para feijoeiro comum irrigado. Revista Ciência e Agrotecnologia, Lavras, v.29, n.1, p.69-76, 2005.

BEM, J.R. et al. Resposta da cultura do feijoeiro (Phaseolus vulgaris L.) à adubação nitrogenada em um Latossolo Roxo distrófico. In: REUNIÃO TÉCNICA ANUAL DO FEIJÃO, 14., 1977, Porto Alegre. Ata... Porto Alegre: IPA, 1977. p.109-112.

BONSANELLO, J. et al. Ensaios de adubação nitrogenada e fosfatada na cultura do feijão na Zona metalúrgica de Minas Gerais. Revista Ceres, Viçosa, v.22, n.124, p.423-428, 1975.

BRAGA, J.M. et al. V inte ensaios de adubação N-P-K da cultura do feijão na Zona da Mata - MG. Revista Ceres, Viçosa, v.20, n.111, p.370-380, 1973.

BUZETTI, S. et al. Efeito da adubação nitrogenada em componentes da produção do feijoeiro (Phaseolus vulgaris L.) cultivado em diferentes densidades. Cultura Agronômica, Ilha Solteira, v.1, n.1, p.11-19, 1992.

COMISSÃO DE FERTILIDADE DO SOLO - CFSRS/SC. Recomendações de adubação e calagem para o Estado do Rio Grande do Sul e Santa Catarina. 3.ed. Passo Fundo: SBCS - Núcleo Regional Sul, 1994. 224p.

COMISSÃO ESTADUAL DE PESQUISA DE FEIJÃO - CEPEF: Recomendações técnicas para o cultivo do feijão no Rio Grande do Sul. Erechim: Comissão Estadual de Pesquisa de Feijão, 2001. 112p.

EMBRAPA. Ambiente de software NTIA, versão 4.2.2: manual do usuário - ferramental estatístico. Campinas: Centro Nacional de Pesquisa Tecnológica em Informática para a Agricultura, 1997. 258p.

EMBRAPA. Centro Nacional de Pesquisa de Solos (Rio de Janeiro, RJ). Sistema Brasileiro de Classificação de Solos. Brasília: EMBRAPA Produção de Informações; RJ: EMBRAPA Solos, 1999. 412p.

KORNELIUS, E. et al. Efeitos de doses e épocas de aplicação de nitrogênio na produção de feijão. In: CONGRESSO BRASILEIRO DE CIÊNCIA DO SOLO, 15., 1975, Campinas. Resumos... Campinas: SBCS, 1975. V.15, p.203-205.

LÚCIO, A.D. Parâmetros da precisão experimental das principais culturas anuais do Estado do Rio Grande do Sul. 1997. 64f. Dissertação (Mestrado em Agronomia) Curso de Pós-graduação em Agronomia, Universidade Federal de Santa Maria.

MIYASAKA, S. et al. Modo e época de aplicação de nitrogênio na cultura do feijoeiro. Bragantia, Campinas, v.22, n.40, p.511-519, 1963.

MORENO, J.A. Clima do Rio Grande do Sul. Porto Alegre: Secretaria da Agricultura, Diretoria de Terras e Colonização, Secção de Geografia, 1961. 46p.

MOURA, R.L. et al. Efeito da inoculação, adubação nitrogenada e molibdênio no rendimento do feijão. 1979, Porto Alegre, RS. In: REUNIÃO TÉCNICA ANUAL DO FEIJÃO 15., 1979, Porto Alegre, RS. Anais... Porto Alegre: Fepagro, 1975. V.15, p. 24-26.

MOURA, R.L. et al. Efeitos da adubação nitrogenada, do espaçamento e densidade de semeadura sobre o rendimento do feijão. In: REUNIÃO TÉCNICA ANUAL DO FEIJÃO 12., 1975, Porto Alegre, RS. Anais... Porto Alegre: Fepagro, 1972. p.101-106. 
OSÓRIO, C.A.S. et al. Efeitos da adubação nitrogenada em feijoeiro (1975/76). In: REUNIÃO TÉCNICA ANUAL DO FEIJÃO 12., 1976, Porto Alegre, RS. Anais... Porto Alegre, Fepagro, 1976. p.68-72.

PONS, A.L. et al. Efeito da adubação nitrogenada em cultivares de feijoeiro. In: REUNIÃO TÉCNICA DO FEIJÃO 11., 1974, Porto Alegre, RS. Anais... Porto Alegre, Fepagro, 1974. V.11, p.19-23.

PONS, A.L. et al. Efeito da adubação nitrogenada, fosfatada e potássica em feijoeiro I. Solo Vacaria (1976/77). In: REUNIÃO TÉCNICA ANUAL DO FEIJÃO 14., 1977, Porto Alegre, RS. Anais... Porto Alegre, Fepagro, 1975. V.14, p.77-78.

PORTES, T. de A. Ecofisiologia. In: ARAÚJO, R.S. (Ed) Cultura do feijoeiro comum no Brasil. Piracicaba: POTAFÓS, 1996. Seção II, p.101-131.

POSSEBON, S.B. et al. Avaliação de genótipos de feijoeiro em duas épocas de cultivo na região da depressão central do Rio Grande do Sul. In: REUNIÃO TÉCNICA ANUAL DO FEIJÃO, 2003, Porto Alegre, RS. Anais... Porto Alegre: Fepagro, 2003. 57p.
RODRIGUES, M.B.; KIEHL, J.C. Volatilização de amônia após emprego de uréia em diferentes doses e modos de aplicação. Revista Brasileira de Ciências do Solo, Campinas, v.10, p.37-43, 1986.

SCOTT, A.J.; KNOTT, M.A. A cluster analysis method for grouping means in the analysis of variance. Biometrics, Raleigh, v.30, n.3, p.507-512, 1974

SILVA, A.J. et al. Resposta de cultivares de feijão (Phaseolus vulgaris L.) à adubação nitrogenada. I - Produção de grãos e seus componentes. Ciência e Prática, Lavras, n.13, v.3, p.348-355, 1989.

SILVA, M.I. et al. Efeito de níveis de aplicação de nitrogênio na produção de feijão (Phaseolus vulgaris L.). Ciência Rural, Santa Maria, v.7, n.4, p.395-401, 1977.

ZAGONEL, J. et al. Perdas na colheita mecanizada da cultura do feijão em função da população de plantas e épocas de aplicação de nitrogênio. In: CONGRESSO NACIONAL DE PESQUISA DE FEIJÃO, 2002, Viçosa, MG. Anais... Viçosa: UFV, 2002. p.596-599. 